\title{
PESCA ARTESANAL E PROJETOS DE DESENVOLVIMENTO EM BITUPITÁ, CEARÁ: OS DIREITOS DAS POPULAÇÕES COSTEIRAS FRENTE AOS INTERESSES EMPRESARIAIS E ESTATAIS ARTISANAL FISHING AND DEVELOPMENT PROJECTS IN BITUPITÁ, CEARÁ: THE RIGHTS OF COASTAL POPULATIONS CONFRONTED WITH THE CORPORATE AND STATE INTERESTS
}

\author{
Lea Carvalho Rodrigues \\ leaufc@gmail.com \\ Doutora em Ciências Sociais pela Universidade Estadual de Campinas (UNICAMP).Professora Associada do \\ departamento de Ciências Sociais da Universidade Federal do Ceará (UFC). \\ Antônia Gabriela Pereira Araújo \\ sociaisufc@gmail.com \\ Mestranda em Sociologia pela Universidade Federal do Ceará (UFC).
}

\section{RESUMO}

O artigo apresenta os diferentes interesses em jogo no processo de expansão das atividades turísticas e projetos de desenvolvimento na região do extremo-oeste do litoral do Ceará. A partir dos dados etnográficos colhidos junto à localidade de Bitupitá, que comporta uma das maiores colônias de pescadores da região e onde ainda se pratica a pesca de curral, o artigo aborda a legislação que estabelece os direitos das comunidades e povos tradicionais, situando os pescadores daquela localidade frente aos direitos estabelecidos e aos interesses estatais e empresariais, tendo em conta o atual contexto de expansão das atividades turísticas, da pesca predatória e da implementação de usinas de energia renovável (eólicas) na região. A situação de mudanças vivida por essas populações, no presente, é abordada à luz dos resultados apresentados por etnografias já clássicas sobre o tema, realizadas no âmbito da antropologia brasileira.

Palavras-chave: Pesca de curral. Turismo.Comunidades tradicionais.

\begin{abstract}
The article presents the different interests involved in the process of expanding tourism-related activities as well as development projects in the far-western coast of the coast of Ceará. Bitupitá holds one of the largest fishing villages in the region, where the practice of the corral fishing is still current. Using the ethnographic data collected there, the article discusses the legislation that establishes the rights of the communities and traditional peoples, placing fishermen in that location before set out rights and state and business interests. The current context of expanding tourism-related activities, overfishing and the implementation of renewable energy plants in the region are taken into account in the discussion. The changes experienced by these populations are addressed in the light of the results presented by now classic ethnographies carried out under Brazilian anthropology on the subject.
\end{abstract}

Keywords: Corral fishing.Tourism.Traditional communities. 


\section{INTRODUÇÃO}

Valemo-nos, neste artigo, dos dados etnográficos coletados desde 2010 na localidade de Bitupitá, praia situada no município de Barroquinha, na costa Oeste do litoral cearense, onde ainda hoje se pratica, de forma intensa, a pesca de curral. A situação vivida pelos pescadores artesanais que ali vivem é aqui analisada na referência a um contexto de fortes mudanças provocadas por políticas de desenvolvimento que estão afetando a região. As mais expressivas e de maior impacto referem-se à expansão do turismo, ao incentivo estatal ao uso de energias renováveis (usinas eólicas) e ao desenvolvimento da carcinicultura (Criação de camarão em viveiros).

Vale ressaltar que, desde o desenvolvimento mais sistemático dos estudos sobre a pesca artesanal, na área das ciências sociais e na antropologia, em particular, um conhecimento mais sistematizado foi se construindo à medida em que se detectavam elementos recorrentes, bem como particularidades como as questões estruturais de teor político, econômico e social e o aparato legal de cada país no ordenamento da atividade. Assim, ao longo do tempo, foi possível alcançar um quadro mais acabado sobre esta atividade e este segmento específico, voltado à produção artesanal e de tanta importância no contexto mundial. Vale pontuar, informa McGoodwin (2001), que os pescadores artesanais representavam, no início deste século, $95 \%$ do contingente total de pescadores em todo o mundo.

Alguns aspectos mais universalizados que caracterizam a pesca artesanal, abordados por pesquisadores nacionais e estrangeiros, dizem respeito ao isolamento total ou relativo das populações pesqueiras, à natureza das relações de trabalho, com ênfase no não assalariamento e na composição de equipes de trabalho segundo as relações de parentesco; às habilidades e conhecimentos sobre o ambiente, à divisão de trabalho dentro da unidade familiar, à baixa produção do pescado, para consumo e com pequeno excedente a ser comercializado; à tecnologia simples, às agruras do ambiente, aos baixos ganhos e à existência de intermediários na fase de comercialização. Dentre os autores que enfatizam estas características destacamos, para o caso brasileiro, os estudos realizados por Kottak $(1966,1982)$ e Forman (1966), sobretudo, quanto à importância conferida a noção de segredo e à mestrança como elementos centrais da ideologia igualitária, considerada pelos estudiosos do tema como marca deste tipo de pesca; Cordell (1989) e o foco nas noções de risco e imprevisibilidade atinentes à produção pesqueira, aspectos já elencados por Forman (1970) e Kottak (1966), mas vistos por este autor como elementos atenuadores do caráter conflituoso da territorialidade marítima; Diegues $(1973,1983)$ e a formulação de critérios de classificação dos pescadores, diferenciando produção artesanal da industrial para, em seguida, avançar na caracterização do caráter tradicional das comunidades pesqueiras e, posteriormente, nas relações e conflitos dessas populações com as unidades de conservação (1994, 1999, 2000); Maldonado (1993) e as contribuições de uma etnografia de caráter comparativo entre pescadores brasileiros, suecos e canadenses ao evidenciar semelhanças estruturais nas relações dos pescadores com o ambiente, na centralidade da ideologia igualitária e no jogo equilibrado entre competição e cooperação na atividade da pesca artesanal.

No caso brasileiro, é importante notar como esses estudos seminais já detectavam a importância dos processos de mudanças vividos pelas localidades estudadas e, mesmo que de forma apenas contextual, já aparecia o turismo como elemento modificador do modo de vida e trabalho dos pescadores, fato que é presente também nos estudos de Britto (1999), Pessanha (2003), Kant de Lima e 
Pereira (1997) em suas contribuições aos estudos sobre pescadores artesanais no estado do Rio de Janeiro. Entretanto, ao longo do tempo e à medida que novos estudos foram produzidos, percebe-se a importância de outros elementos que ganham destaque em obras mais recentes, como a seguir.

McGoodwin (2001), buscando compreender a complexidade própria à atividade da pesca artesanal, chama a atenção para o baixo poder político existente nessas comunidades, o que as torna vulneráveis às ameaças colocadas pela pesca industrial. Ainda do ponto de vista político, enfatiza a subordinação dessas populações às instituições governamentais, o que ressalta a importância do Estado como agente relevante em todo o processo, uma vez que, como também observa o autor, a ordem comunitária é distinta daquela colocada pelas autoridades governamentais.

Marín (2007), por sua vez, se vale das premissas de McGoodwin em seu estudo etnográfico sobre as características econômicas e sociais da pesca artesanal na costa mexicana. Enfatiza algumas características também gerais a este tipo de produção pesqueira, destacando o fato de pesca e vida social nessas pequenas localidades seguirem o ritmo dos ciclos da natureza e afirmando que, se por um lado, nesta atividade, o trabalho tem prevalência sobre o capital, com a dependência dos recursos naturais e a vulnerabilidade ao seu esgotamento, esta mesma situação induz os esforços para a sua preservação. Em razão desta dependência homem-natureza é que nessas comunidades pesqueiras as tensões proveem, especialmente, dos perigos de contaminação marinha, dos movimentos mais intensos de capitais e pessoas resultantes da dinâmica global do capitalismo contemporâneo e da expansão do turismo sobre esses ecossistemas, um dos fatores que mais impacta as atividades da pesca artesanal.

A produção acadêmica brasileira que dialoga com a antropologia da pesca, sobretudo, a que se firmou após os anos 1970, revela, em seu processo de desenvolvimento, alguns movimentos interessantes para a reflexão sobre mudanças nas propostas teóricas e metodológicas e na amplitude da análise. Inicialmente, nota-se a existência de etnografias sobre a pesca com forte delimitação dos recortes empíricos, centrados no presente etnográfico, com a ausência de um aprofundamento histórico e a elaboração de um quadro contextual mais amplo. É o caso dos estudos desenvolvidos por Chaves (1973), Pessanha (1977) e Kant de Lima (1978), à exceção de Mourão (1971), quanto à perspectiva histórica, e Diegues (1973), que tanto contextualiza quanto historiciza o objeto, elencando e articulando elementos estruturais e os níveis micro e macro analíticos. Ainda nas décadas seguintes algumas obras mantêm essa característica então predominante, como Britto (1999), Maldonado (1993) e Telles (2002), mas a tendência é a de incorporar história e contexto às análises, com negação à noção de equilíbrio, traço das análises funcionalistas e estrutural-funcionalistas de períodos anteriores que permaneceram em muitas obras antropológicas, como a tendência a compor a totalidade. Evidentemente, as críticas que marcaram a produção antropológica a partir de meados dos anos 1980 foram orientadoras das mudanças ocorridas: crítica aos modelos fechados, subversão da relação sujeito objeto, constatação da necessidade de novos instrumentais teóricos e metodológicos para o estudo de processos, indivíduos e grupos em fluxo e ação; a crítica à especialização do conhecimento e à ausência de foco nas relações de poder, com o postulado de que a antropologia deve se posicionar frente ao objeto e exercer a crítica. Isto redundou no esforço de elaboração de etnografias com maior amplitude empírica e analítica, com reformulação de conceitos como os de sociedade e cultura - não mais referidos a uma totalidade - bem como de identidade e gênero - não mais fixos e homogêneos, como esclarece Caldeira (1988). 
Outra faceta das mudanças na produção brasileira em antropologia da pesca, e à qual damos especial relevância, diz respeito à forma como a ação do Estado, por meio da legislação e de suas políticas públicas, figura nas análises. Desse ângulo, observa-se que até os anos 1990 as abordagens iam desde a ausência total do Estado, tanto na referência a contexto como a análise, como os estudos desenvolvidos por Chaves (1973) e Kant de Lima (1978), a uma abordagem menos aprofundada sobre este aspecto, como as realizadas por Pessanha (1977) e Britto (1989) sobre a pesca no estado do Rio de Janeiro e Maldonado (1993) sobre os pescadores de João Pessoa, Paraíba, à exceção de Diegues (1973) em cuja análise as ações estatais são muito presentes. Nas abordagens mais recentes, a tendência se inverte, sendo poucos os estudos que ignoram a presença do Estado, como os de Paes (1998) e Telles (2002); ou o abordam com menor aprofundamento analítico como o fazem Silva (1993) e Knox (2007), preponderando estudos que dialogam seguidamente com as ações estatais, entre eles Nunes (2003), Saldanha (2005) Moura (2009), Costa (2011), Pereira (2011) e Lopes (2013). Há ainda os que dão especial atenção ao aparato legal que ordena essas atividades, como o foco sobre a legislação da posse da terra, no Brasil, em Carolino (2010).

Estudos mais recentes sobre o tema, realizados no Sul do Brasil (RIAL; GÓDIO, 2006), também procedem a uma contextualização abrangente e focalizam os processos de mudança com atenção especial às abordagens de gênero, à fragmentação das unidades familiares durante o processo de mudanças e às novas configurações da economia local, decorrentes da expansão do turismo, bem como às mudanças sociais experimentadas pelos pescadores.

Para os interesses do presente artigo, consideramos a importância das abordagens que enfocam os processos históricos e políticos que produzem as transformações vividas pelas populações costeiras, no mais das vezes marcadas pelo conflito, bem como do conjunto significativo de agentes, relações e interesses envolvidos. Postulamos, ainda, que é necessário se debruçar sobre o conteúdo das políticas, bem como o aparato legal, em todas as dimensões que afetam essas populações, para, compreendendo as fragilidades delas frente ao arcabouço legal e às instâncias estatais e seus órgãos reguladores, fornece elementos para questionar a dinâmica que aproxima Estado e interesses político-econômicos.

Nossa proposta metodológica conjuga a perspectiva colocada por Little (2006) para o estudo de conflitos socioambientais, com mapeamento dos atores e interesses envolvidos e as propostas de análise de políticas públicas desenvolvidas por Lejano (2012), com foco na noção de experiência, e Rodrigues $(2008,2011,2013,2014)$ na formulação de eixos analíticos, dentre os quais destacamos, para este artigo, a análise de conteúdo das políticas.

Tal proposta tem nos permitido perceber com clareza a natureza das mudanças e os principais agentes nesse processo, com atenção especial às políticas que produzem essas mudanças, sua lógica, os efeitos possíveis, sua coerência e a existência ou não de mecanismos garantidores dos direitos legais. O acompanhamento do processo, ao longo desses cinco anos, nos permite tomar como indicativo que as diferentes políticas em ação numa mesma localidade colocam os sujeitos frente à necessidade de desenvolver avaliações que orientem suas escolhas, bem como os situa frente a alguns impasses. Guiamo-nos, ainda, pela ideia de que quanto maior o número e a diversificação das políticas em ação, mais se exacerbam algumas práticas locais, como as relações clientelistas; por outro lado, pode ocorrer o reforço das identidades locais.

Salientamos, ainda, que os estudos que vimos realizando na localidade de Bitupitá porta algumas características particulares que a tornam instigante 
ao estudo da atividade pesqueira: i) trata-se de uma localidade que até o ano de 2014 se mantinha num relativo isolamento, com dificuldade de acesso pela inexistência de estrada de rodagem asfaltada e difícil comunicação por tecnologia digital; ii) a pesca ainda é a base da economia local e os recursos naturais ainda são abundantes, embora já haja sinais de sua diminuição; iii) é a única localidade da costa cearense onde a pesca de curral ainda é exercida de forma intensiva; iv) os modos de vida e de trabalho são condizentes com as características apontadas pelos primeiros estudos sobre a pesca artesanal no Brasil. Evidentemente, os contextos mudaram, bem como os modelos político/econômicos adotados no país, o acesso à informação e a percepção das pessoas sobre seus direitos, o que produz a expectativa de uma profícua contribuição aos estudos no campo da antropologia da pesca.

\section{PRAIA DE BITUPITÁ: O CONTEXTO ETNOGRÁFICO}

Bitupitá é um distrito do município de Barroquinha, localizado na costa ocidental do litoral cearense e segundo os dados do IBGE, de 2010, contacom uma área absoluta de $383,46 \mathrm{~km}^{2}$, uma população de 14.476 pessoas, sendo 9.770 os residentes em áreas urbanas e 4.706 na área rural. Os moradores de Bitupitá fazem parte deste contingente de habitantes da zona rural, totalizando cerca de quatro mil indivíduos, conforme dados fornecidos pelo Programa Saúde da Família (PSF). O acesso à cidade é feito por rodovia estadual que, saindo de Fortaleza, percorre todo o litoral Oeste do estado do Ceará e interliga a cidade de Barroquinhaaos municípios de Camocim e Jijoca de Jericoacoara, estando todos eles no trajeto de um importante roteiro turístico, intitulado Rota das Emoções, que faz o percurso de Jijoca de Jericoacoara, no Ceará, a Barreirinhas, no Maranhão, porta de entrada para os Lençóis Maranhenses, o que coloca todos os municípios que se encontram neste tramo, e que possuem atrativos naturais, na rota da expansão do turismo no Ceará. Uma pequena área da praia de Bitupitá está inserida na APA-Delta do Parnaíba, dotada de extraordinária riqueza natural, com dunas, manguezais e grande biodiversidade no estuário dos riosTimonha e Ubatuba.

Essa região possui uma paisagem diversificada de dunas, áreas de coqueirais, carnaubais e vegetação rasteira. A população que habita os lugarejos na área rural vive da agricultura e da coleta de mariscos nos escoadouros dos rios acima referidos e ainda do pequeno comércio de produtos alimentícios. Já nas localidades litorâneas o forte é a pesca de linha e de curral.

Bitupitá tem um número pequeno de ruas, paralelas à orla marítima, ficando a área central de comércio mais intensivo, escolas, igrejas e posto de saúde na área mais afastada da praia. Já na beira-mar e suas adjacências residem os pescadores. Um ponto importante é a ausência de documentos de posse das residências, ainda que alguns moradores afirmem ter contratos particulares de venda efetuados pelo cartório local. Isto se repete em quase todas as áreas litorâneas do estado do Ceará ainda não urbanizadas ou ocupadas pelo turismo. $\mathrm{O}$ fato das famílias ali residirem há gerações lhes dá tranquilidade quanto à posse e, como ressalta Rodrigues (2010), a terra não é vista como mercadoria. Os dados da pesquisa mostram que, praticamente, a totalidade das crianças e jovens em idade escolar não se dedica às atividades produtivas e as entrevistas com as famílias mostrou o desejo unânime de que os filhos sigam outras profissões, menos árduas e melhor remuneradas.

A Colônia de Pescadores Z-23, localizada em Bitupitá, atende aos interesses dos pescadores não só desta praia como também da redondeza, e há, 
ainda, o Sindicato de Pescadores e Pescadoras da Praia de Bitupitá, fundado em 2012 pelo filho de um pescador, que tem se dedicado a facilitar a aposentadoria de pescadores e marisqueiras não cadastrados na Colônia de Pesca. Um ponto a destacar é que Bitupitá, assim como todo o município de Barroquinha, é dominada por dois grupos políticos que se revezam no poder, sendo que o presidente da colônia de pescadores é membro de uma das duas famílias detentoras de poder político local.

\section{A PESCA ARTESANAL EM BITUPITÁ}

No âmbito da antropologia brasileira, a primeira dissertação sobre pesca de curral (CHAVES, 1973) voltou-se, em especial, ao estudo da organização do trabalho dos pescadores artesanais na localidade de Almofala, no Ceará. Tal estudo nos é de especial importância, pois Almofala se situa na mesma região de nossas pesquisas atuais, que, à época, concentrava o maior número de currais de pesca no estado. Hoje, como dissemos, Bitupitá é a única localidade da costa cearense onde se realiza a pesca intensiva de curral e a existência de um estudo sobre a mesma atividade e região, realizado há quarenta anos, permite a comparação com os dados atuais.

A pesca de curral é conhecida também por pesca de cerco fixo ou armadilha fixa e são algumas características geográficas da costa da praia de Bitupitá que favorecem o desenvolvimento deste tipo de pesca, tais como as amplitudes das marés, os terrenos de fraca declividade e a existência de baixios próximos às margens ${ }^{1}$. Trata-se de uma técnica de pesca artesanal que captura peixes de médio e até de grande porte. Os pescadores, orientados pelos fluxos das marés, instalam grandes cercados a distância de uma e até duas milhas da costa (entre 1600 a 3200 quilômetros). Essas armadilhas chegam a medir de 400 a 700 metros de comprimento por 6 a 12 metros de altura. São construídas geometricamente com varas e mourões - madeiras roliças - fincados em águas rasas ou profundas, redes de nylon e telas de arame que revestem toda a estrutura de madeiramento do curral.

Já mostrava Chaves (1973) que a construção de um curral de pesca não se dá de forma aleatória, desde a escolha do ponto de fixação da armadilha. O local é escolhido de acordo com a natureza do solo onde serão fixados os mourões e de acordo com as carreiras d'água e o sentido dos ventos. Um ponto interessante é a forma como se estabelecia a propriedade do "chão do curral". Uma vez que o terreno marinho era marcado pela primeira vez ali se instalava o "marcador", indivíduo responsável pela tarefa de fixar o local onde os mourões serão colocados, o que estabelece o dono daquele chão (hoje, o termo utilizado é terreno) sendo possível, após o seu registro na capitania dos portos, a venda ou arrendamento a estranhos; também cabendo transferir a posse de pais para filhos. No presente, não existe a possibilidade de expandir o número de currais naquela área, mas esta atividade sempre conferiu ao marcador uma grande importância na territorialização do espaço marinho e um respeito e prestígio semelhantes ao que grande parte da literatura sobre a pesca artesanal atribui ao mestre das equipes de pesca quando da descoberta de pesqueiros, locais que a partir de sua descoberta e posterior publicização tornam-se posse da equipe para a exploração dos recursos marinhos. Em especial, chamamos a atenção para os estudos desenvolvidos por Forman (1970), Kottak (1966), Cordell (1989) e Maldonado (1993). Vale notar, também, que os atuais marcadores são antigos mestres de embarcação.

Em Bitupitá, constatamos que a maioria dos moradores vive exclusivamente da pesca e das atividades relacionadas a ela durante todos os períodos do 
ano, isto é, tanto no inverno quanto no verão os pescadores realizam a atividade pesqueira como única fonte de renda, não havendo a articulação comumente encontrada entre pesca e agricultura apontadas por Acheson (1981), Diegues (1983) e Maldonado (1993). Na época da safra, inverno, eles realizam a despesca e na época da entressafra, verão, realizam os consertos e a construção de currais. A praia é o local onde acontece a maioria das atividades ligadas à pesca, como a construção e o conserto dos apetrechos de trabalho. Também ali são feitas as esteiras, tratando-se de imensas telas de arame que medem até 12 metros de altura por vinte metros de comprimento. Utilizadas na construção dos currais, são fixadas aos mourões de forma a promover o fechamento da armadilha. Na praia também ocorrem as relações de sociabilidade e a negociação do pescado. Quanto à divisão do trabalho, a pesca de curral é, conforme ocorre de forma generalizada na atividade pesqueira, uma prática majoritariamente exercida por homens, embora as mulheres participem de outras tarefas como a construção de malhas de redes e a coleta de mariscos. Algumas atuam na pesca de rede em águas rasas, nas pesqueiras e na confecção e conserto de redes e apetrechos de pesca.

A observação das diferentes fases do processo de trabalho do pescador de curral e, de forma mais ampla, das técnicas, conhecimentos e estratégias desenvolvidos nesta atividade produtiva, mostra que ela é meticulosa, fruto de planejamento, perspicácia, observação e conhecimento minucioso da natureza, em aprimoramento constante. Esse conhecimento, como expõe Cunha (2007), se desenvolveu pela interação dos pescadores com as regularidades e com a diversidade da natureza, no aprendizado e domínio de sua dinâmica complexa, constituindo-se em saberes que se materializam nas práticas pesqueiras. Assim, notamos que currais de beira (mais próximos à praia), currais de meia carreira (a meio caminho entre os currais de beira e os de fundo) e currais de fora (situados a até três quilômetros da orla) exigem cálculos diferenciados quanto à força dos ventos e das marés, o que define o material que deverá ser utilizado para a feitura das telas, sendo obrigatório o uso do arame para aqueles localizados a maior distância. Dependendo do local onde são instalados o material é modificado, adequado à nova situação. Evidentemente há razões econômicas e ambientais que estão envolvidas nessas diferenças entre currais de beira, de meia-carreira e currais de fora, sobretudo porque a área do curral é tratada como terreno, adquirido e registrado, e fatores ambientais como a pesca predatória têm impulsionado os donos de currais a construírem cada vez mais nas regiões de fundo, mas estes são aspectos que não iremos aqui tratar detalhadamente. O que importa reter é a lógica que rege todo o processo e as diferentes etapas do trabalho. Uma vez que os currais têm uma durabilidade inferior a um ano, em média, nove meses, os pescadores se envolvem seguidamente em diferentes atividades, como as de reparo e reposição de mourões, arames e outros materiais que compõem a sua estrutura.

Desta forma, a pesca artesanal de curral compõe um processo de trabalho bastante complexo, pois comporta diversas etapas entre terra e mar: desde os trabalhos entre as matas e estradas, quando do transporte da madeira para preparação de mourões, na praia, a preparação dos arames e telas, bem como das esteiras; depois, no mar, a construção dos currais, que envolve várias fases: a marcação, o soterramento dos mourões e o revestimento dos mesmos com as esteiras; e, por fim, a despesca (retirada dos peixes da armadilha), que envolve outros trabalhadores com habilidades específicas de lançamento da rede, mergulho e manejo das mesmas no fundo do mar, bem como a sua condução à superfície, repletas de peixes para carregamento nos barcos que estão à espera. Mas há ainda as tarefas de manutenção de barcos e currais e, consequentemente, um número mais elevado e mais diversificado de técnicas e habilidades envolvidas. 
Chaves (1973) elencou cinco categorias de trabalhadores que se alternavam entre "trabalhos de terra" e "trabalhos de mar". Na fase dos trabalhos de terra atuavam os "tiradores de madeira" e os "tecedores de arame"; nos "trabalhos de mar" sobressaíam os "vaqueiros", "ajudantes" e o "canoeiro". O marcador é uma função para a qual é preciso perícia, habilidade, rigor, ordem, conhecimento, observação, destreza e cálculo. Chaves, em vista a estas características da atividade, denominou todo o processo de feitura de um curral como "tecnologia artesanal" (1973, p. 55).

Nossa pesquisa, realizada com um intervalo de aproximadamente quarenta anos, mostra, hoje, um número maior de categorias de trabalhadores durante os serviços efetuados no mar. Na marcação do chão do curral, os trabalhos do marcador são feitos com o auxílio de mais cinco homens, denominados "batedores de mourão". Note-se ainda que tanto no passado, como no presente a estrutura física do curral permanece, inalterada, composta de uma espia, a linha de mourões enfileirados até a entrada do primeiro compartimento, que deve guiar os peixes para o interior da armadilha, e os compartimentos dentro dela: a sala grande, a salinha e o chiqueiro, locais onde os peixes ficam definitivamente aprisionados. Tanto na Almofala de 1973 como na Bitupitá atua no processo de construção é o mesmo: primeiro é estabelecida a marca do primeiro mourão, o chamado mourão mestre, na parte central do chiqueiro.

Ainda quanto às categorias de trabalhadores, nas pesquisas recentes realizadas em Bitupitá, encontramos um número mais extenso de denominações também para as atividades da despesca, a retirada dos peixes do cerco: "vaqueiros" e "mata-vaqueiros", as figuras centrais na condução do trabalho de retirada do peixe dos currais e embarque nos botes; mas também o "lançador", os "mergulhadores" e o "boqueiro", este último incumbido de ficar na boca do chiqueiro, prendendo a rede ao fundo com os pés, para que os peixes não saiam; este deve, também, ao final da varredura, fechar a rede nas suas partes superior e inferior. Já os mergulhadores têm a tarefa de conduzir a rede rente às esteiras e aos mourões que formam as paredes da armadilha de forma a fazer uma varredura no chiqueiro e capturar os peixes. Cinco mergulhadores revezam-se entre fundo do mar e superfície, até que a rede tenha percorrido todo o chiqueiro. Há um rodízio de atividades durante o processo da despesca e, ao exercerem as diferentes atividades, são atribuídas novas classificações aos sujeitos, conforme as funções que passam a executar.

Quanto ao tipo de atividade que envolve todo o processo da pesca de curral, Chaves (1973), ainda que considerasse a pesca de curral como uma atividade produtiva eminentemente artesanal, dada a pluralidade de pessoas envolvidas e a diferença entre elas quanto à propriedade - quem detém e controla os recursos tecnológicos e os que não o fazem--, considerou que a atividade como um todo se assemelhava a uma unidade produtiva, uma empresa, onde alguns buscam a subsistência (os que não têm os meios tecnológicos) e outros o lucro (os que ficam com a maior parte dos ganhos auferidos com a pesca); lucro para o qual os primeiros contribuem. Assim, ele considerou que apenas na fase que ele denominou "levante", de revestimento do curral com as esteiras, é que ocorreria uma tarefa que se poderia considerar como apoiada na reciprocidade de serviços. É quando as turmas de trabalho em um dado curral ajudam outros com os quais mantém vínculos sociais mais fortes na difícil tarefa de transporte das esteiras e fixação aos mourões.

Este dado é de extrema relevância e deve ser colocado a uma reflexão mais detalhada, uma vez que, ao estabelecer o tipo de atividade que é realizada por esses trabalhadores do mar, define-se, também, a que categoria pertence este trabalhador: artesanal e tradicional, ou industrial. 
Diegues (1973) elencou cinco dimensões principais na caracterização da pesca artesanal: relações de trabalho, tecnologia, tradição de pesca, comercialização e ambiente ecológico. Para o autor, o pescador artesanal trabalha sozinho ou em equipes formadas por familiares e tem controle total ou parcial dos meios de produção e do processo de trabalho. Ademais, "é o próprio pescador artesanal que faz ou conserta os aparelhos de pesca, movimenta a embarcação, procura os locais apropriados para a captura, pesca e vende o produto" (p. 112). Um elemento importante que está presente nessa caracterização é a autonomia do pescador, a "liberdade" que o diferencia do pescador embarcado (DIEGUES, 1983). Isto fica bastante claro, também, na exposição das diferenças e conflitos entre os pescadores de canoas e de botes referidos por Robben (1994). A essa liberdade e autonomia se agregam os conhecimentos adquiridos ao longo do tempo, a experiência e o aprendizado com os mais velhos. Outro elemento importante apontado por Diegues (1983) é a amizade, o companheirismo e a solidariedade existentes na equipe. Afirma o autor que o maior fator de distinção entre a pesca artesanal e a industrial seria o que ele denomina de "corporação de ofício", ou seja, o sentimento expresso pelos pescadores artesanais de formarem um grupo que detém uma profissão, conhecimentos e técnicas específicas que lhes confere o sentido de pertencimento e, portanto, de identidade. E mesmo quando existem formas variadas de relações de trabalho e de domínio dos meios de produção o autor indica outro elemento de diferenciação: o controle do processo de trabalho que distingue a pequena produção da grande empresa capitalista. Cita casos também em que ocorre o que ele denomina "parceria", situações em que não há um controle total nem sobre os meios de produção nem sobre o processo de trabalho. Exemplifica com o caso dos pescadores de lagosta do Espírito Santo em que o pescador tem a rede, mas não o barco, sendo o resultado dividido pelo sistema de partes ${ }^{2}$.

Sobre este ponto, consideramos que, embora a pesca de curral seja em seu conjunto uma atividade de grande porte e as habilidades sejam mais diversificadas, todos os pescadores envolvidos no processo se revezam nas tarefas e, ainda, trabalham em atividades de conserto dos materiais de pesca, sendo, portanto, um trabalho altamente cooperativo e sob o qual eles têm total controle. O caráter cooperativo marca todo o processo de despesca, a divisão da produção é por partes e além do curral ser o local da pesca e do ganho, confere aos pescadores autonomia, confiança e prestígio, por seus conhecimentos e habilidades específicas. Ainda que eles não sejam proprietários de todos os meios de produção - o curral pode pertencer a um antigo pescador e os botes que transportam os pescadores podem pertencer a outro que não o dono do curral - é uma atividade que envolve grupos familiares e as habilidades na profissão são transmitidas de pais para filhos, o que, aliado aos saberes e conhecimentos e ao domínio de todo o processo de trabalho, caracteriza a atividade como pesca artesanal, diferenciando-a da industrial, diferentemente do afirmado por Chaves (1973).

O sucesso da pesca de curral depende do conhecimento sobre o movimento espontâneo dos peixes na plataforma continental. Segundo depoimentos dos pescadores de curral, a técnica dessa pesca reside no fato dos peixes seguirem as sombras dos mourões e das varas da espia, projetadas na água durante o dia. Este seria o fator determinante na condução do peixe para o interior da armadilha. Após ter seguido a sombra dos mourões e varas da espia o cardume tenta desviar-se do obstáculo denominado sala grande, mas não encontrando passagem entra na salinha, de onde não consegue mais sair, indo depois para o último compartimento, o chiqueiro, cerco em onde o peixe é capturado.

Destacamos, ainda, que a técnica de bater o mourão e fincá-lo verticalmente na plataforma continental é umas das etapas mais difíceis da construção 
do curral e, por isso, informada por um vasto saber sobre o meio aquático. São necessários mais de mil mourões para a construção de curral de médio porte, de quinhentos metros de comprimento. Um grupo de nove homens finca 15 mourões por dia, demorando cerca de noventa dias para finalizar a tarefa. Primeiramente, os mourões são posicionados a cada braça (medida que equivale a 1,5 metros) e as varas a meia braça. Para fincar os mourões os homens utilizam um martelo de madeira e um cavalete fixado ao fundo do mar com âncora. Os martelos de madeira chegam a pesar dez quilos cada e dois homens os utilizam, revezando as marretadas e equilibrando-se em cima do banco. Um terceiro batedor terá a tarefa de afundar o mourão e levá-lo até o local onde este deverá ser fincado. Com o auxílio de uma corda, amarrada ao pé de outro mourão, afunda-se o mourão que está flutuando à superfície pela força do empuxo exercida sobre ele e o pescador consegue levá-lo até o local onde ele deverá ser fincado.

Já no momento da despesca sobressaem os aspectos cooperativos, o revezamento de funções, a precisão, a habilidade e o domínio dos conhecimentos sobre o mar. Ao se aproximarem do curral, os pescadores amarram a canoa na sua parte externa, tarefa exercida principalmente pelo encarregado. Após amarrada a canoa, o vaqueiro e o mata-vaqueiro submergem, segurando a rede e entram no chiqueiro através de uma abertura existente nesse mesmo compartimento. Um desses dois pescadores irá realizar a função de "boqueiro": ficará na entrada do "chiqueiro", segurando um dos dois calões da rede com o pé. O "boqueiro" terá que se equilibrar com um dos pés em cima de um mourão da "boca do chiqueiro" enquanto que o outro pé estará impulsionando o calão da rede para baixo de forma que não permita a saída de nenhum peixe, isto é, o calão terá que ficar rente com o outro mourão da boca do chiqueiro. Enquanto isso, três pescadores já estarão distribuídos em lugares diferentes do chiqueiro a uma distância de dois metros um do outro para realizarem a função de mergulhadores. Os outros dois pescadores realizam também a atividade de mergulho. Ao mergulhar, o pescador encosta os pés na superfície do mar e segura o pé do calão, enquanto o outro mergulhador segura o calão na superfície. O que mergulhou terá que caminhar para frente, segurando-se com uma das mãos nos mourões do chiqueiro e, com a outra mão, levando o calão rente a areia e a estrutura de esteiras do compartimento. $\mathrm{O}$ mergulhador que segura o calão na superfície terá que empurrá-lo para baixo, no intuito de não deixá-lo flutuar, mas também caminhará para frente de forma que o calão acompanhe os movimentos abaixo d'água. Passados cerca de dois minutos, no máximo, o homem na superfície mergulhará e o que está submerso emergirá. Este procedimento se repete até vinte vezes de forma que o calão passe pelas mãos dos cincos mergulhadores (dependendo da condição física, cada um pode mergulhar até quatro vezes) ${ }^{3}$. Este procedimento pode ser realizado duas ou três vezes no mesmo dia, até todos os peixes serem retirados, podendo o trabalho chegar a um total de quatro horas. Após as despescas, ainda durante o dia, os vaqueiros permanecem nos currais consertando as varas, os mourões; as malhas e as esteiras de arame que foram destruídas pelas ondas são ainda substituídas; além disso, eles fazem a limpeza dos currais, retirando as cracas que se fixam na madeira, tornando-a fraca, completando as fases do processo de trabalho.

\section{MUDANÇAS EM CURSO E OS DIREITOS DOS PESCADORES ARTESANAIS}

O estado do Ceará, assim como outros estados da região Nordeste do país, vem adotando estratégias de desenvolvimento socioeconômico voltadas à valorização e à remodelação das áreas litorâneas, explorando seus atrativos naturais com o objetivo de expansão do turismo, bem como aproveitando o 
potencial de seus ventos para a produção de energia renovável, pela implantação de usinas eólicas. O turismo na costa Oeste do litoral do Ceará tem sido favorecido pelas ações em torno do roteiro turístico Rota das emoções: Jeri-Delta-Lençóis ${ }^{4}$, por meio do Programa de Desenvolvimento ao Turismo (PRODETUR/NE), formulado dentro das diretrizes do Ministério do Turismo (MTur). Já a produção de energia renovável, em crescimento desde 2004, tem como fator relevante a criação do Programa de Incentivo às Fontes Alternativas de Energia Elétrica (PROINFA); ambos os programas têm como agente da maior relevância na região o Banco do Nordeste (BNB).

Quando iniciamos os trabalhos de pesquisa em Bitupitá, em 2010, o vilarejo tinha difícil comunicação com os arredores e a sede do município: a estrada de piçarra seguia por quase quarenta quilômetros e em épocas de chuvas, ou quando o barro endurecia e nela se formavam buracos, a travessia era bastante penosa. Eram poucos os locais para hospedagem, três pousadas e aluguel de quartos em um bar, além de serem bastante precárias as instalações; o comércio era majoritariamente de produtos alimentícios; a assistência médica estava restrita ao posto de saúde local, durante a semana, e a vida ali transcorria de forma pacata: os pescadores, saindo com os barcos pela madrugada, negociando o peixe até o meio da manhã, trabalhando ao longo da praia, alguns na parte da manhã, outros na parte da tarde. A praia era tomada pelas crianças pequenas nadando e acompanhando as atividades dos adultos na lida com os barcos e a pesca, as mulheres tratando os peixes nas pesqueiras, o peixe salgando ao sol, estendidos em inúmeros varais, ali mesmo, na beira da praia; os homens estendendo e trançando as esteiras na areia e, ao final da tarde, os jovens praticando esportes como o futebol e o voleibol, enquanto mulheres e homens se postavam a frente das casas, dos bares e bodegas, até o cair da noite.

No final de 2014 foi concluída a estrada asfaltada e, a partir de então, muita coisa mudou. As últimas viagens de campo, em janeiro e julho de 2015, permitiram-nos coletar informações sobre os acontecimentos mais recentes. No ano novo, o lugarejo recebeu um número expressivo de visitantes - os moradores afirmam que chegaram mais de duas mil pessoas à localidade; já está ocorrendo o treinamento de jovens para atuar como garçons; o número de pousadas passou a sete; há demanda junto aos pescadores para a realização de passeios de barcos com turistas; já se faz passeios às praias adjacentes e já antevendo a especulação imobiliária terrenos começaram a ser cercados, inclusive, na área próxima ao mangue, para onde escoam as águas do rio Timonha. Especificamente sobre a pesca, já se constatam várias mudanças: uma empresa do Sul do país está comprando o peixe, as pesqueiras onde antes muitas mulheres trabalhavam estão fechando, muitas se transformando em garagens. Outra informação coletada diz respeito aos resultados da excelente safra de pescado em 2013 que, segundo eles, "enricou muita gente". Informações preliminares também indicam que estes recursos que ingressaram na localidade tendem a se direcionar para as atividades turísticas.

Como se vê, a região que estudamos está em processo acelerado de mudanças e isto em razão de políticas de incentivo ao turismo, de incentivo à implantação de formas de energia renováveis (usinas eólicas) e de expansão da piscicultura e carcinicultura (criadouros de espécies em cativeiro). Todas essas políticas demandam a posse de terras por parte de grandes empresários que atuam no setor, sendo um elemento central para o desenvolvimento das três atividades elencadas. E essa demanda atinge diretamente os pescadores, marisqueiras e pequenos agricultores locais já que as áreas de interesse empresarial são as que essas populações habitam e sobre a qual não detêm a propriedade da terra. 
No caso do turismo, a atividade precisa de terras para se fixar e se expandir, mas não em qualquer área e sim naquelas de grande beleza, como as praias e os acidentes geográficos com vista para o mar. Os pescadores vivem exatamente nos locais de interesse do capital turístico e o que tem ocorrido em toda a orla brasileira, como já relatava Diegues (1983) sobre os acontecimentos da década de 1970 no litoral paulista, é a venda das terras pelos pescadores aos pequenos e grandes empresários do ramo com seu deslocamento para zonas periféricas, afastando-os da praia e reduzindo seu espaço de trabalho, bem como a migração para atividades turísticas. Sobre os efeitos do turismo e as mudanças mais recentes no litoral do país vide Adomilli (2006), Gódio (2006), Knox (2009), Rodrigues (2010, 2011), Silva (2012).

Atualmente, tendo já acompanhado o processo vivido por outras comunidades da redondeza e com o apoio de organizações não governamentais, muitas localidades têm reagido às ameaças de perda da terra, reivindicando judicialmente a sua posse $\mathrm{e}^{5}$ ou transformando-as em reserva extrativista, enquanto outras se veem fragilizadas frente às estratégias do capital turístico imobiliário (RODRIGUES, 2010; 2011) e, enredadas em conflitos internos e disputas pela terra, têm dificuldades para uma tomada de posição unânime sobre a questão. Por outro lado, quando confrontamos os princípios que orientam a Política Nacional de Turismo e os mecanismos de sua implantação, notamos algumas contradições e insuficiências para que ela atinja o que se propõe, em especial, o objetivo de desenvolvimento e inserção social dessas comunidades tradicionais (2003, 2007, 2013). Rodrigues (2011) expõe esses elementos contraditórios e a difícil compatibilização entre esses objetivos, orientados por paradigmas opostos e conflitantes, o que redunda em pouca garantia dos direitos das populações tradicionais residentes nas áreas de interesse do capital turístico, assegurados em lei, bem como a premissa do baixo impacto ambiental, já que os órgãos estaduais e federais que emitem as licenças ambientais, como tem mostrado nossa pesquisa, nem sempre são isentos.

Quanto ao incentivo à energia renovável, as usinas eólicas necessitam de terras normalmente em regiões de dunas, próximas às praias, o que afeta o acesso dos pescadores ao mar, dos coletores aos mangues e gera impactos nocivos ao ambiente com a construção e manutenção das usinas. Afirma Meireles (2011) que as usinas eólicas têm causado sérios impactos ambientais negativos. Toda a movimentação nas dunas para a fixação artificial dos aerogeradores e manutenção dos equipamentos altera os campos de dunas do ponto de vista morfológico, topográfico e fisionômico, causando danos a sítios arqueológicos e a privatização dos sistemas ambientais de interesse das comunidades tradicionais que residem nessas áreas.

Já para o desenvolvimento de atividades como a carcinicultura, as mais incentivadas pela Política Nacional de Pesca cuja meta é triplicar os números atuais nos próximos cinco anos, os criadouros de camarão são construídos em áreas próximas às praias e mangues, em terras cedidas pela União, o que além de representar uma diminuição das áreas reivindicáveis pelos pescadores artesanais, afeta profundamente o ecossistema manguezal com "extinção de habitats da fauna e da flora, as ameaças à biodiversidade e à exaustão dos recursos marinhos" (BRASIL, 2011) como o desmatamento de vegetação de mangues, perda de diversidade genética, bloqueio das entradas das marés com alterações nos regimes hídricos, descarte de resíduos contaminantes nas águas das gamboas e considerável prejuízo às formas de sobrevivência das populações tradicionais.

As duas últimas políticas se fazem com a concessão de terras da União e, se examinarmos os seus textos orientadores, veremos como os objetivos e metas são condizentes com a visão de mercado, do agronegócio, ocupando o ambiente e as populações residentes na área um lugar periférico na política 
(BRASIL, 2015). A tônica, no caso da aquicultura é que a atividade representa "nova fronteira para crescimento do agronegócio" e que é "construída em parceria com o setor produtivo", sendo objetivos claros facilitar o crédito e agilizar a cessão de terras do domínio da União (BRASIL, 2015, p. 18-27).

No caso de Bitupitá, localidade atingida pelas três políticas e habitada por um número elevado de pescadores pobres, sujeitos a regimes de trabalho intensivos e que não detém a propriedade de suas habitações, um dos pontos principais é refletir sobre a forma como essas mudanças podem afetar a classificação desses pescadores e suas famílias como comunidades tradicionais e as condições deles reivindicarem o território que habitam e do qual retiram sua sobrevivência, como preconiza a Política Nacional de Desenvolvimento Sustentável dos Povos e Comunidades Tradicionais (PNPCT).

O decreto $\mathrm{n}^{\circ} 6.040$, de 07 de fevereiro de 2007, pelo qual o governo brasileiro instituiu a PNPCT define povos e comunidades tradicionais como "grupos culturalmente diferenciados e que se reconhecem como tais", com formas de organização social próprias, com a ocupação de territórios e uso de recursos naturais "como condição para a sua reprodução cultural, social, religiosa, ancestral e econômica", valendo-se de práticas e saberes transmitidos pela tradição. Mas como observa Carolino (2010), ainda que esses direitos se vinculem à noção de território, na prática, no plano legal, o conceito não tem sido acionado.

Já no campo acadêmico, a definição de comunidades tradicionais tem nas formulações de Diegues (1999, 2001) e Almeida (2008) importantes referenciais teóricos. Diegues define comunidades tradicionais como grupos humanos que se diferenciam culturalmente, caracterizados por: simbiose com a natureza e um conhecimento aprofundado sobre ela, transmitido de geração em geração; um modo de vida construído nessa inter-relação; noção de território que delimita a área que o grupo ocupa para morada e trabalho e no qual se reproduz; o exercício de atividades de subsistência ainda que haja relação com o mercado; a baixa acumulação de capital e pouca divisão do trabalho, sobre o qual o grupo detém controle sobre todo o processo, constituindo-se em práticas artesanais; tecnologia simples e reduzido impacto ambiental, além da importância atribuída à unidade familiar, às práticas culturais e à auto identificação como comunidades tradicionais. Já Almeida acentua o caráter político da forma de denominação, preferindo comunidades tradicionais a populações tradicionais em razão de considerar o segundo conceito esvaziado de seu sentido político à medida que adentrou a esfera governamental. Segue o mesmo sentido político dado por Cunha e Almeida (2009) ao conceito de populações tradicionais, que nessa formulação se refere a grupos que lutam por se afirmar como tais e fazer valer os direitos que esta condição lhes garante.

Pelo exposto, os pescadores de Bitupitá e arredores se classificam como comunidades tradicionais, tanto no âmbito acadêmico como no plano legal. No entanto, entendemos que o rápido processo de mudanças vivido no presente pelo vilarejo, sobretudo com o incremento populacional, a especulação imobiliária que se avizinha, a chegada paulatina de estrangeiros, as mudanças no tratamento do pescado e na forma da sua comercialização e os apelos vindos da expansão turística, sobretudo o baixo nível associativo que caracteriza os pescadores de Bitupitá, se comparados à atuação de outras comunidades pesqueiras próximas, pode facilmente reduzir suas chances de reivindicação dos referidos direitos.

Um caso de sucesso, o dos pescadores de Maceió, praia vizinha a Bitupitá, em disputa judicial com um grande grupo imobiliário por terras situadas na orla marinha, é relatado por Rodrigues (2011). Ocorre que, em Bitupitá, 
a forte divisão dos moradores, segundo o pertencimento a partidos políticos, representados por dois grupos familiares que se opõem e que se alternam no poder, dificulta as ações coletivas. Na localidade, todos os possíveis benefícios públicos entram na lógica do desenvolvimento das relações clientelistas, similar às características conferidas por Robben (1994) à dinâmica da economia pesqueira na localidade baiana de Camurim, onde, segundo o autor, as ações eram pautadas pela amizade, troca de favores (como votos pela obtenção de aval para empréstimos) e manipulações de todas as ordens. Assim é em Bitupitá: pescadores pobres partidários do grupo perdedor podem deixar de perceber recursos provenientes de benefícios oficiais como os recursos do Programa Bolsa Família e do Programa de Erradicação do Trabalho Infantil (PETI); além de ver prejudicados os acessos aos serviços médicos, aos cargos na administração pública, como vagas e cargos nas escolas e postos de saúde e outras atribuições existentes. De forma inversa, os adeptos dos vencedores podem alcançar todos os benefícios e cargos, mesmo que não atendam a todas as exigências oficiais ou técnicas. Como diz uma das entrevistadas: "Assim se conseguem as coisas em Bitupitá, tudo sempre pela política". Para ela, este é o grande problema de Bitupitá, pois nas localidades próximas os constrangimentos e as trocas de favores ocorrem em especial na época das eleições, enquanto em Bitupitá isto faz parte do cotidiano e marca o modo de vida da localidade. No caso dos pescadores, isto se reflete diretamente sobre sua situação de trabalho, uma vez que a presidência da colônia de pescadores, desde a sua fundação, em 1919, está em mãos do mesmo grupo político, o que pode dificultar os pescadores mais pobres, muitos sequer capazes de pagar a mensalidade da colônia e outros que são impossibilitados de se filiar em razão do uso da entidade como instância de controle político local, o que os impede de receber os benefícios oficiais, como é o caso do seguro defeso.

Ocorre, ainda, que Bitupitá, estando no trajeto do roteiro turístico Rota das Emoções e sendo uma das localidades do Ceará com maior potencial de desenvolvimento desta atividade depois de Jericoacoara, tem direcionado para a localidade políticas públicas de melhoria de infraestrutura, como o recente asfaltamento da estrada que interliga a localidade à sede do município, bem como projetos de urbanização da praia e melhorias no sistema de transportes. Neste sentido é que, tendo acompanhado processualmente o modo de vida da localidade e as mudanças que vêm ocorrendo, desde o ano de 2014, podemos inferir que o afluxo maior de políticas tende a exacerbar as práticas acima elencadas. Como bem observa Kottak (2009), quem, tendo realizado a sua pesquisa em Arambepe na década de 1960, procedeu a um acompanhamento sistemático das mudanças, nas décadas posteriores, a grande contribuição dos estudos longitudinais é que eles permitem desenhar um quadro processual das mudanças aceleradas que vêm atingindo milhares de comunidades em todo o mundo.

Nas últimas viagens de campo a Bitupitá, percebemos que as recentes mudanças demandaram de vários grupos sociais o acionamento de sua rede de relações no plano político para assegurar ganhos advindos das mudanças ou impedir prejuízos. A localidade próxima, Venâncio, habitada por um grupo familiar extenso, acionou políticos da esfera estadual com representatividade local para alterar os planos de deslocamento da estrada, o que prejudicaria as atividades comerciais de alguns moradores que constituem a liderança local e detém um pequeno comércio às margens da rodovia. Também os donos de veículos que fazem o trânsito dos moradores entre Bitupitá e a sede do município uniram-se em busca da interferência de um deputado estadual com base eleitoral na localidade. $\mathrm{O}$ intuito era evitar que uma empresa de um município vizinho ganhasse da prefeitura a concessão do transporte, o que mostra também uma relação conflituosa entre a localidade e a sede do município. 
Quanto aos pescadores, o processo de mudanças também os coloca frente a alguns impasses e necessidades de escolhas. A chegada do turismo abre-lhes a possibilidade de ganho extra no período da entressafra, quando coincide com a festividade religiosa mais importante da localidade, a Festa de Santa Adelaide, que atrai um número elevado de visitantes. O mesmo ocorre no período de carnaval e, mais recentemente, com a inauguração da estrada, também aos finais de semana. Os pescadores são demandados pelos turistas para a realização de passeios de canoa pela orla e até a região do Pontal, onde ocorre o encontro entre águas dos Rios Timonha, Ubatuba, seus afluentes e o mar, formando um pequeno delta ou, ainda, a algumas praias mais distantes. Os pescadores, até o presente, têm atuado de forma clandestina porque para exercerem a atividade legalmente teriam que se registrar no Cadastur, perdendo a condição de pescador profissional, o que a maioria rejeita. Não ter o registro de pescador profissional os impediria do acesso a linhas de crédito especiais, aos benefícios do Programa Bolsa Família, quando é o caso, à aposentadoria na referida categoria e ao seguro defeso, mas também à perda de uma identidade profissional. Este impasse e a necessidade de escolhas os levam a refletir sobre direitos e sobre a profissão, e, no geral, tem reforçado os sentimentos de pertencimento à categoria de pescadores, o que não significa que isto persista indefinidamente, dado que os dados de pesquisas realizadas em regiões que há décadas já experimentaram processos de mudança dessa natureza indicam a tendência ao paulatino afastamento da atividade pesqueira, inserção nas atividades de turismo, com modificações no modo de vida e, quando o pescador continua na atividade, também mudanças nas atividades de trabalho (DIEGUES, 1983; KOTTAK, 1982, 2009; PESSANHA, 2003; ADOMILLI, 2006).

Além do mais, quem estiver mais bem situado politicamente, seja porque no momento seu grupo está no poder ou sua rede de relações lhe permite o acesso a indivíduos que podem atendê-lo em diferentes âmbitos, terá melhores condições de se movimentar e auferir ganhos com as mudanças, obtendo uma licença para abrir um negócio em local turístico, como já vem ocorrendo com concessões de autorização para instalação de barracas nasareias da praia. Um ramo do grupo familiar da localidade de Venâncio, por exemplo, iniciou a atuação no ramo de transportes, com o tempo abriu um comércio de alimentos e mais recentemente uma pequena pousada, o que indica um processo em curso de fortalecimentodos grupos de podere a emergência de uma elite empresarial local.

\section{CONSIDERAÇÕES FINAIS}

Dois foram os objetivos principais deste artigo: reforçar a importância das abordagens processuais e propor aportes metodológicos que possibilitem articular antropologia e políticas públicas, perspectiva considerada fundamental ao entendimento dos processos de mudança vividos pelas comunidades tradicionalmente estudadas pelos antropólogos. Como argumentam Rodrigues; Ortolan e Gonçalves (2014) o fato dessas populações situarem-se em áreas geográficas de grande interesse do Estado e do capital, em seus diferentes domínios, e a situação frágil em que se encontram frente aos interesses em jogo pede uma atenção especial sobre a importância do diálogo entre os dois campos disciplinares.

Como proposta, nos valemos do quadro metodológico desenhado por Little (2002) para o estudo dos conflitos socioambientais, baseado na etnografia multiator que permite identificar os diferentes agentes sociais envolvidos em uma situação, as interações entre eles e com os meios biofísico e social. Desta perspectiva, tanto os pescadores como os empresários, os políticos e as agências estatais, em sua complexa dinâmica relacional e na efetivação do jogo políticoou nas escolhas mais imediatas, como decidir-se por abrir mão ou não da cate- 
goria de pescador, mudar ou não o apoio a um grupo partidário - depende dos movimentos tanto na esfera macro (as políticas públicas e a orientação política das esferas mais altas de poder) como das microrrelações, tanto nas interações sociais cotidianas como na relação com a natureza.

A esta perspectiva metodológica, sugerimos a incorporação dos quatro eixos analíticos propostos por Rodrigues $(2008,2014)$ para a análise e avaliação de políticas públicas, quais sejam, as análises: de conteúdo, de contexto, da trajetória institucional e do espectro temporal e territorial da política, sendo que, no presente artigo, nos limitamos a referir-nos ao conteúdo das políticas. Esta formulação tem a inspiração em Lejano (2012) e em sua proposta de análise centrada na experiência, na compreensão de como as políticas são vividas e experienciadas por uma multiplicidade de atores. Quando analisamos a situação em que se encontram os pescadores que desejam auferir um ganho extra com o turismo e se veem na contingência de escolher entre se cadastrar ou não junto aos órgãos oficiais de turismo, é esta noção de experiência - como uma vivência por meio da qual o sujeito se constrói (TURNER, 1986) - que orienta o seu modo de agir. Assim, o mapeamento dos atores nos permite detectar interesses, alianças, conflitos e escolhas, enquanto o estudo das políticas nos permite perceber seus entrecruzamentos, as divergências de orientações, as lacunas e contradições e a noção de experiência nos revela como, frente a este complexo de interesses e facetas do jogo político, os indivíduos se posicionam por meio de suas avaliações e escolhas. No caso em tela, evidentemente, fica claro que os diferenciais de poder fazem pender a balança para os detentores de poder local e, se por um lado, acirram a contenda entre os grupos rivais, por outro, subjugam ainda mais aqueles situados em posição inferior no campo de forças.

\section{NOTAS}

${ }^{1}$ Para uma descrição mais detalhada vide Araújo (2013); Araújo e Gonçalves (2015) e Araújo, Aragão e Gonçalves (2014).

${ }^{2}$ A respeito, e nessa mesma direção, veja a abordagem de Ramalho (2012).

${ }^{3}$ Para uma melhor apreciação sobre o processo vide Araújo (2013).

${ }^{4}$ O Rota das Emoções é um roteiro turístico que teve sua origem no ano de 2007 (a respeito vide RODRIGUES; SANTOS, 2012), quando da assinatura de um convênio pelos estados do Ceará, Piauí e Maranhão, com apoio do Ministério do Turismo (MTur). O financiamento é com recursos da Cooperação Andina de Fomento (CAF) e Banco Interamericano de desenvolvimento (BID), em conjunto com Banco do Nordeste (BNB) e apoio do Serviço Brasileiro de Apoio às Micro e Pequenas Empresas (Sebrae) e Secretarias de Turismo dos estados envolvidos, visando a implementação de um roteiro turístico que inclui os municípios de Jijoca de Jericoacoara, Camocim, Chaval, Cruz e Barroquinha, no Ceará; as cidades de Ilha Grande, Parnaíba, Luis Correa e Cajueiro da Praia, no Piauí; e as cidades de Barreirinhas, Paulino Neves, Tutóia, Santo Amaro e Araioses, no Maranhão, considerados de grande potencial turístico.

${ }^{5}$ A respeito desses movimentos reivindicatórios veja também Carolino (2010).

\section{REFERÊNCIAS}

ACHESON, James M. Anthropology of Fishing, Annual Review of Anthropology, v.10, p. 275-316, 1981.

ADOMILLI, Gianpaolo Knoller. Território e mobilidade: notas sobre a relação entre global e local em uma comunidade pesqueira, 2006. 
ARAÚJO, Antonia Gabriela P. Modos de saber, fazer e viver: uma etnografia dos guardiões de currais da praia de Bitupitá (Barroquinha-CE). Monografia de conclusão de curso de graduação em Ciências Sociais, Departamento de Ciências Sociais, Universidade Federal do Ceará, 2013.

GONÇALVES, Bruno. "Mar de vaqueiros": conhecimentos tradicionais da pesca de curral e os direitos territoriais dos pescadores artesanais de Bitupitá, Ceará. Tessituras, v. 3, n. 1, p. 231-269, jan/jun 2015.

ARAGÃO, Lorena L.; RODRIGUES, Lea C. Turismo, populações tradicionais e ambiente, Gaia Scientia, volume especial, p.161-171, 2014.

BRASIL - CÂMARA DOS DEPUTADOS. Relatório Síntese GT Carcinicultura: Comissão de defesa do consumidor, meio ambiente e minorias da Câmara dos deputados. Relatório Final. Disponível em: <http://www2. camara.leg.br/atividade-legislativa/comissoes/comissoes-permanentes/cmads/ gruposdetrabalho/legislatura-2007-a-2011/RELATORIO-CARCINICULTURA-FINAL.pdf>., 2011. Último acesso em: 20 abr. 2016.

. Ministério da Pesca e Aquicultura (MPA). Plano de Desenvolvimento da Aquicultura Brasileira - 2015/2020, Brasília, 2015.

. Ministério do Turismo. Plano Nacional de Turismo 2003/2007: diretrizes, metas e programas, 2003.

. Plano Nacional de Turismo, 2007/2010: uma viagem de inclusão. Ministério do Turismo, 2007.

. Plano Nacional de Turismo 2013/ 2016: O Turismo fazendo muito mais pelo Brasil, 2013.

BRITTO, Rosyan Campos de C. Modernidade e tradição: construção da identidade social dos pescadores de Arraial do Cabo, RJ. Niterói: EDUFF, 1999.

CAROLINO, Kátia. Direitos territoriais das comunidades tradicionais: um estudo de caso da comunidade da Ilha monte de Trigo, São Sebastião (SP). Dissertação de mestrado, PROCAM/USP,2010.

CHAVES, Luís de Gonzaga Mendes Chaves. Trabalho e subsistência -

Almofala: aspectos da tecnologia e das relações de produção. Dissertação de Mestrado em Antropologia Social, MN/UFRJ, 1973.

CORDELL, John. A sea of Small Boats. Cambridge: Cultural Survival, 1989.

. Marginalidade social e apropriação territorial marítima na Bahia. In: DIEGUES, A.C.; MOREIRA, A.C.C. (Orgs.), Espaços e recursos naturais de uso comum. São Paulo, NUPAUB/USP, 2001.

..; McKEAN, Margaret A. Sea Tenure in Bahia, Brazil. In: Proceddins of the Conference on Common Property Resource Management. Washington, D.C.: NationalAcademyPress, 1986.

CUNHA, Lucia Helena de O. Ordens e desordens socioambientais; saberes tradicionais em dinâmicas pesqueiras da costa paranaense. Tese de doutorado em meio ambiente e desenvolvimento, UFPR, 2007.

CUNHA, Manuela C.; ALMEIDA, Mauro W. B. Populações tradicionais e conservação ambiental. In: CUNHA, Manuela Carneiro, Cultura com aspas e outros ensaios. São Paulo: Cosac Naif, 2009.

COSTA, Paula Chamy P. Interações sociológicas na pesca à luz da etnoecologia abrangente: a praia de Itaipu, Niterói, Rio de Janeiro. Tese de doutorado, IFCH/UNICAMP, 2011.

DIEGUES, Antonio Carlos S. Pesca e marginalização no litoral paulista.

Dissertação de mestrado, FFLCH/USP, 1973.

1983.

. Pescadores, camponeses e trabalhadores do mar. São Paulo: Ática, 
. Biodiversidade e comunidades tradicionais no Brasil: os saberes tradicionais e a biodiversidade no Brasil. São Paulo: NUPAUB/USP, 1999.

. O mito moderno da natureza intocada. 3. ed. São Paulo: HUCITEC, 2001 [1994, 1998].

FORMAN, S. The raft fishermen. Bloomington: Indiana University Pressa, 1970.

KANT DE LIMA, Roberto. Pescadores de Itaipu: A Pescaria da Tainha e a Produção Ritual da Identidade Social. Dissertação de mestrado em antropologia, MN/UFRJ, 1978.

PEREIRA, Luciana F. Pescadores de Itaipu: meio ambiente, conflito e ritual no litoral do Estado do Rio de Janeiro. Niterói, RJ: EDUFF, 1997.

KNOX, Winifred. Vivendo do mar: modos de vida e de pesca. Natal: Ed. UFRN, 2009.

KOTTAK, Conrad Phillip. The structure of equality in a brazilian fishingcommunity. Columbia: University of Columbia, 1966.

. Assaulton paradise: Social Change in a BrazilianVillage, New York:

McGraw-Hill, 2006.

. The globalization of a Brazilian Fishing Community, General

Anthropology, v. 16, n. 1, 2009.

LEJANO, Raul. P. Parâmetros para análise de políticas: a fusão de texto e contexto. Campinas: Arte Escrita, 2012.

LOPES, Alissandra Pinheiro. Territorialidades em conflitos na Baía de Sepetiba, Rio de Janeiro, Brasil. Dissertação de mestrado, PROCAM/USP, 2013.

McGOODWIN, J. R. Understanding the Culture of Fishing Communities: a key to fishieries management and food secutiry. Food and Agriculture Organization of the United Nations - FAO/ONU, 2001. Disponível em: <http:// www.fao.org/3/a_y1290e/y1290e05.htm\#bm05>.

MALDONADO, Simone Carneiro. Mestres \& Mares: espaço e indivisãona pesca marítima. São Paulo: Annablume, 1993.

MARÍN GUARDADO, Gustavo. Vidas contramarea: pesca artesanal, desarrollo y cultura en la costa de Michoacán. México: CIESAS: El Colegio de Michoacán, 2007.

MEIRELES, Jeovah A. Danos socioambientais originados pelas usinas eólicas nos campos de dunas do Nordeste brasileiro e critérios para definição de alternativas locacionais. Confins - Revista franco-brasileira de geografia, $\mathrm{n}$. 11, 2011.

MOURA, Gustavo G.M. Águas da Coréia: uma viagem ao centro do mundo em uma perspectiva etnooceanográfica. Recife: Nupeea, 2012.

MOURÃO, Fernando A. A. População do litoral sul do Estado de São Paulo: um estudo de sociologia diferencial, FFLCH/USP, 1971.

NUNES, Márcia. Do passado ao futuro dos moradores tradicionais da Estação Ecológica Juréia-Itatins/SP. Dissertação de mestrado em geografia física, FFLCH/USP, 2003.

PAES, Silvia Regina. Espaço da vida, espaço da morte na trajetória caiçara. Dissertação de mestrado em sociologia, UNESP-Araraquara, 1998.

PEREIRA, Bárbara Elisa. Crianças caiçaras de Guaraqueçaba - PR: relações com a natureza. Dissertação de mestrado, PROCAM/USP, 2011.

PEREIRA, Luciana Freitas. Revisitando Itaipu: um ensaio de antropologia visual. In: LIMA, Roberto Kant de; PEREIRA, Luciana F. Pescadores de Itaipu: Meio ambiente, conflito e ritual no litoral do Estado do Rio de Janeiro. Niterói, RJ: EDUFF, 1997. 
PESSANHA, Elina G. F. Os companheiros: Trabalho e sociabilidade na pesca de Itaipu. Niterói, RJ: EDUFF, 2003.

ROBBEN, Antonius C.G.M. Conflictin Discourses of Economy and Society in: CoastalBrazil, Man, New Series, vol. 29, n. 4, p. 875-900, dec. 1994.

RAMALHO, Cristiano Wellington Noberto. Sentimento de corporação, cultura do trabalho e conhecimento patrimonial pesqueiro: expressões socioculturais da pesca artesanal. Revista de Ciências Sociais, Fortaleza, v. 43, n. 1, p. 8-27, 2012.

RIAL Carmen; GÓDIO, Matías (Org.). Pesca e turismo: etnografias da globalização no litoral do Atlântico Sul. Florianópolis: NUPPE/CFH/UFSC, 2006.

RODRIGUES, Lea Carvalho. Propostas para uma avaliação em profundidade de políticas públicas sociais. AVAL Revista Avaliação de Políticas Públicas, Fortaleza, a. I, v.1, n.1, p. 7-15, jan-jun, 2008.

. Turismo, empreendimentos imobiliários e populações tradicionais

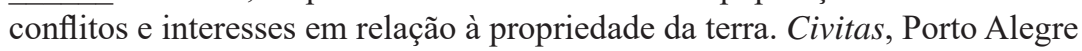
v. 10 n. 3, p. 527-544, set.-dez. 2010.

. Diretrizes da Política Nacional de Turismo e Subsídios para a sua avaliação. Revista Gestão Pública: práticas e desafios, Recife, v. 1, p. 62-78, 2011.

. Avaliação de políticas e programas sociais: princípios teórico-metodológicos para uma avaliação em profundidade. In: FLORENCIO, Ana Maria G.; DIÓGENES, Elione Maria N.; CAVALCANTE, Maria do Socorro A. de O. (Orgs.) Políticas públicas e estado capitalista: diferentes olhares e discursos circulantes. Alagoas: Edufal, 2013.

. Turismo como estratégia de desenvolvimento na América Latina:

dilemas e perspectivas de um modelo excludente. In: CARVALHO, Alba Maria P.; HOLANDA, Uribam X. Brasil e America Latina: Percursos e dilemas de uma integração. Fortaleza: Editora UFC, 2014.

RODRIGUES, Lea Carvalho; SANTOS, Potyguara Alencar. Populações tradicionais, turismo e conflitos territoriais. Estudo etnográfico em Tatajuba, Ceará. Cadernos do LEME, Campina Grande, v. 4, n. 1, p. 67-93. Jan./Jun. 2012.

ORTOLAN, M.H.; GONÇALVES, A. F. Antropologia e Políticas Públicas: dos encontros históricos ao diálogo teórico e metodológico. In: RODRIGUES, Lea. C.; SILVA, Isabelle B.P., Saberes locais, experiências transnacionais: interfaces do fazer antropológico. Fortaleza: Expressão Gráfica: ABA Publicações, 2014.

SALDANHA, Iaskara Regina R. Espaços, recursos e conhecimento tradicional dos pescadores de manjuba (anchoviellaLepidentostole) e Iguape/SP, PROCAM/USP, 2005.

SILVA, Luiz Geraldo S. Caiçaras e jangadeiros: cultura marítima e modernização no Brasil. São Paulo: CEMAR, 1993.

SILVA, Rubens Elias da. Guiado por mares e peixes: memória social, inovação tecnológica e o processo de fragmentação na pequena pesca comercial simples em duas comunidades costeiras do Rio Grande do Norte. (Tese de doutorado) em sociologia, UFPB, 2012.

TELLES, Anamaria. Sereias e anequins: uma etnografia visual com um grupo de pescadores artesanais da Barra da Lagoa, Dissertação de mestrado em antropologia, UFSC, 2002.

TURNER, Victor. Dewey, Dilthey, and Drama: An Essay in the Anthropology of Experience. In: TURNER, Victor; BRUNER, Edward, (Eds.), The Anthropology of experience. Urbana: University of Illinois Press, 1986. 